\title{
Avoidable mortality in Europe 1955-1994: a plea for prevention
}

\author{
Lorenzo Simonato, Terri Ballard, Pierantonio Bellini, Regina Winkelmann
}

\begin{abstract}
Objective-To analyse trends of avoidable mortality in Europe, emphasising causes of death amenable to primary prevention through reduction of exposures, secondary prevention through early detection and treatment, and tertiary prevention through improved treatment and medical care.
\end{abstract}

Design-Descriptive study of mortality from avoidable causes for the years 1955 through 1994, for ages 5-64 at time of death. Using the World Health Organisation Mortality Database, five year death rates were standardised to the world population.

Setting-21 countries of Europe in four regions (northern, central, and southern Europe, Nordic countries).

Participants-All causes of deaths for men and women, aged 5-64, at time of death.

Main results-Between 1955-59 and 199094 , the reduction in mortality was somewhat greater for avoidable causes than for all causes: $45.8 \% v 45.1 \%$ (women) and $39.3 \% v 32.6 \%$ among men. Reductions in mortality were greater for causes amenable to improved medical care: $77.9 \%$ among women and $76.3 \%$ among men. The smallest reduction in mortality was seen in women for causes amenable to secondary prevention $(11.0 \%)$, and in men for causes amenable to primary prevention including tobacco related conditions $(16.6 \%)$. From a geographical point of view, there were slight differences in trends between European regions, but overall the patterns were similar.

Conclusions-The greatest reduction of avoidable mortality in Europe from 1955-94 came from causes amenable to improved treatment and medical care for both sexes. Further reductions of avoidable mortality can be achieved through implementation of primary and secondary prevention activities, such as tobacco control, reduction of occupational exposures, and universal access to breast and cervical cancer screening programmes. (F Epidemiol Community Health 1998;52:624-630)

The use of "avoidable death" as an indicator of the quality of medical care stems from work initiated in the United States. In 1976, Rutstein et al proposed a list of sentinel health events to be used as outcome indices to evaluate the quality of medical care and preventive services. ${ }^{1}$ This list has been adapted by investigators in the 1980s and 1990s for the purpose of identifying causes of death that are influ- enced by quality of health care services and resources. ${ }^{2-9}$ Holland and collaborators, supported by the Commission of the European Community, published and subsequently updated a European Community Atlas of "Avoidable Death". ${ }^{10}$ For most of these individual studies and the atlas, avoidable mortality was used principally as an indicator of the quality of health care resources and national health policy, whether investigating geographical variations within a country or trends over time in various regions or countries. It is commonly held that death rates from avoidable causes, given they are correctly defined, should decrease faster than death rates from nonavoidable causes when health care is efficient. ${ }^{411} 12$

We present here the results of a descriptive analysis of avoidable mortality trends from 1955 to 1994 in Europe, for ages 5-64, carried out with the goal of identifying trends of mortality from avoidable causes amenable to primary prevention, reduction of exposures; secondary prevention, early detection and early treatment; and tertiary prevention, improvements in treatment and medical care.

\section{Methods}

From the mortality database of the World Health Organisation, we extracted for the countries included in the analysis all deaths for men and women aged 5-64, as well as corresponding population data by sex and age class, for single years from 1955 to 1994. Death rates were calculated for five year periods starting in 1955 using the world population, ages 5-64, as the standard. We considered Europe as a whole (21 countries) and by four quadrants of Europe, as shown in table 1. Avoidable mortality among the four defined regions within Europe were compared to highlight differences possibly associated with varying health care systems, socioeconomic characteristics, and lifestyle factors. Mortality data were not available uniformly by country for the earlier and later years of the study period (table 1).

Table 2 lists the causes of avoidable mortality chosen for this study. A conversion table of the International Classification of Disease, Injuries and Causes of Death (ICD) from the 7th to the 9th revision was used to ensure comparability of data series (table 2). Whenever possible, causes from Rutstein's original classification of avoidable conditions were included. ${ }^{1}$ All of the avoidable causes of death from Charleton's basic group and the European Community Atlas of Avoidable Deaths ${ }^{210}$ were included with the exception of deficiency anaemias. Furthermore, several causes of death not frequently found in other classifications of avoidable 
Table 1 European countries and years of mortality data availability

\begin{tabular}{|c|c|c|}
\hline Country & $\begin{array}{l}\text { Period of data } \\
\text { availability }\end{array}$ & $\begin{array}{l}\text { (years not available for } \\
\text { individual causes) }\end{array}$ \\
\hline \multicolumn{3}{|l|}{ A Southern Europe } \\
\hline Italy & $1955-92$ & \\
\hline Greece & $1961-94$ & $\begin{array}{l}1961-65\left({ }^{\star}+\S\right) ; \\
1961-63(\mathbb{\Phi})\end{array}$ \\
\hline Malta & 1967-94 & $1968-77(\ddagger)$ \\
\hline Portugal & 1955-94 & $\begin{array}{l}1955-79\left(^{\star}+59\right) ; \\
1971-79(\ddagger)\end{array}$ \\
\hline \multirow{2}{*}{\multicolumn{3}{|c|}{ B Central Europe }} \\
\hline & & \\
\hline Austria & 1955-94 & $1955-68(\dagger)$ \\
\hline France & 1955-93 & \\
\hline West Germany & $1955-93$ & $1955-67(\dagger)$ \\
\hline Switzerland & $1955-94$ & \\
\hline \multicolumn{3}{|l|}{ C Northern Europe } \\
\hline Belgium & $1955-89$ & \\
\hline $\begin{array}{l}\text { England and } \\
\text { Wales }\end{array}$ & 1955-94 & \\
\hline Ireland & 1955-92 & \\
\hline Luxembourg & 1967-94 & $1972-78(\ddagger)$ \\
\hline Netherlands & 1955-94 & \\
\hline Northern Ireland & $1955-94$ & \\
\hline Scotland & $1955-94$ & \\
\hline \multicolumn{3}{|l|}{ D Nordic countries } \\
\hline Denmark & $1955-93$ & \\
\hline Finland & 1955-94 & \\
\hline Iceland & $1961-94$ & \\
\hline Norway & $1955-93$ & \\
\hline Sweden & $1955-93$ & \\
\hline
\end{tabular}

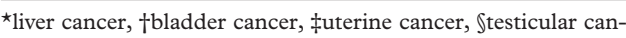
cer, $\uparrow$ Hodgkin's disease.

mortality were also included: tumours of the upper airways and digestive tract, liver, bladder, and female breast, leukaemias, and deaths by injury or poisoning. Twenty four causes or groups of causes were assigned to three separate groups. Group one refers to causes of death that may be preventable through primary prevention, that is, by reducing the incidence of disease. This group includes causes whose aetiology in part is attributable to lifestyle factors, most importantly the use of alcohol and tobacco (circulatory disturbances of the brain, tumours of the upper digestive and respiratory tract, lung, and bladder, liver) and other conditions connected principally to the consumption of alcohol (chronic liver diseases). In addition, several of the tumours in this group also have occupational aetiology (lung, bladder, liver). ${ }^{13-16}$ Group one also includes deaths caused from injury and poisoning, which are influenced in part by legal and societal measures such as traffic safety (speed limits, use of seat belts and motorcycle helmets, manufacture of safer vehicles), and crime reduction policies. Group two refers to causes that are amenable to secondary prevention through early detection and treatment. This group includes tumours of the breast and cervix for which screening modalities have been established, and melanoma of the skin for which death is avoidable through early detection combined with adequate treatment. ${ }^{17} 18$ Tumours of the "body of the uterus" and the "uterus parts unspecified" are also included in this group because inconsistent coding on death certificates in some European countries makes it difficult to disaggregate these causes from malignant neoplasms of the cervix. Group three refers to causes that are amenable to improved treatment and medical care. Mortality from infectious diseases is affected in large part by antibiotic treatments and vaccinations as well as cleaner water and food supplies. Changes in mortality for other conditions in this group, such as those requiring medical and surgical intervention (hypertension, ulcers, complications of pregnancy, appendicitis, hernia, cholelithiasis) are related to complex interactions within the health care system, such as accurate diagnoses, transport to hospital, adequate medical and surgical care.

We attempted to estimate the impact of missing data for five causes from six countries (table 1) on the calculation of death rates within avoidable mortality cause groups. We did so by calculating the crude male death rate for one year (1960) during the period of missing data for the first avoidable mortality group. The rate was calculated in two ways: (a) by treating the missing data in 1960 for Greece (liver and bladder cancers), Portugal (liver and bladder cancers), Austria (bladder cancer), and West Germany (bladder cancer) as zeros, and (b) by substituting the zeros with the average annual number of deaths based on the the first

Table 2 Categorisation of causes of avoidable mortality

\begin{tabular}{|c|c|c|c|}
\hline Causes of death & $I C D-7$ & $I C D-8$ & $I C D-9$ \\
\hline \multicolumn{4}{|l|}{ Group 1 Causes avoidable through primary prevention } \\
\hline malignant neoplasms of upper airways and digestive tract & $140-150,161$ & $140-150,161$ & $140-150,161$ \\
\hline malignant neoplasms of the liver & 155 & 155 & 155.0 \\
\hline malignant neoplasms of the trachea, bronchus, and lung & $162-163$ & 162 & 162 \\
\hline malignant neoplasms of the bladder & 181 & 188 & 188 \\
\hline circulatory disturbances of the brain & $330-334$ & $430-438$ & $430-438$ \\
\hline chronic liver disease and cirrhosis & 581 & 571 & 571 \\
\hline injury and poisonings & $800-999$ & $800-999$ & $800-999$ \\
\hline \multicolumn{4}{|l|}{ Group 2 Causes avoidable through early detection and treatment } \\
\hline malignant neoplasms of the skin. ( melanoma and non-melanoma) & $190-191$ & $172-173$ & $172-173$ \\
\hline malignant neoplasms of the female breast & 170 & 174 & 174 \\
\hline malignant neoplasms of the cervix uteri & 171 & 180 & 180 \\
\hline malignant neoplasms of the uterus & $172-174$ & 182 & 179,182 \\
\hline \multicolumn{4}{|l|}{ Group 3 Causes avoidable through improved treatment and medical care } \\
\hline infectious and parasitic diseases & 001-138 & $000-136$ & 001-139 \\
\hline malignant neoplasms of the testis & 178 & 186 & 186 \\
\hline Hodgkin's disease & 201 & 201 & 201 \\
\hline leukaemias & 204 & $204-207$ & $204-208$ \\
\hline chronic rheumatic heart disease & $410-416$ & 393-398 & $393-398$ \\
\hline hypertensive disease & $440-447$ & $400-404$ & $401-405$ \\
\hline diseases of respiratory system & $470-527$ & $460-519$ & $460-519$ \\
\hline gastric and duodenal ulcer & $540-541$ & $531-533$ & $531-533$ \\
\hline appendicitis & $550-553$ & $540-543$ & $540-543$ \\
\hline abdominal hernia & $560-561,570$ & $550-553,560$ & $550-553$ \\
\hline cholelithiasis or other gallbladder disorder & $584-585$ & $574-575$ & $574-575.1$ \\
\hline maternal mortality & $640-689$ & $636-678$ & $630-676$ \\
\hline
\end{tabular}


Table 3 Rates for avoidable mortality in Europe for years 1955-1994, ages 5-64

\begin{tabular}{|c|c|c|c|c|c|}
\hline \multirow[b]{3}{*}{ Calendar years (time periods) } & \multicolumn{5}{|c|}{$\begin{array}{l}\text { Age standardised death rates (world population) } \\
\text { per } 100000 \text { person years }\end{array}$} \\
\hline & \multirow[b]{2}{*}{$\begin{array}{l}\text { Overall } \\
\text { mortality }\end{array}$} & \multicolumn{4}{|c|}{ Avoidable mortality } \\
\hline & & total & $\stackrel{\operatorname{group}}{1+}$ & group 2 & group 3 \\
\hline \multicolumn{6}{|l|}{ Women } \\
\hline $1955-59$ & 244.1 & 130.7 & 52.7 & 24.2 & 53.8 \\
\hline $1960-64$ & 220.6 & 117.4 & 50.9 & 24.5 & 42.0 \\
\hline $1965-69$ & 208.8 & 111.7 & 51.3 & 24.7 & 35.6 \\
\hline 1970-74 & 196.0 & 106.7 & 51.7 & 24.7 & 30.3 \\
\hline $1975-79$ & 178.3 & 97.0 & 49.7 & 23.7 & 23.6 \\
\hline $1980-84$ & 158.8 & 85.1 & 45.6 & 22.8 & 16.6 \\
\hline $1985-89$ & 143.0 & 76.0 & 40.4 & 22.4 & 13.2 \\
\hline 1990-94 & 134.1 & 70.8 & 37.4 & 21.6 & 11.9 \\
\hline \multicolumn{6}{|l|}{ Rate difference per 100000 person years from } \\
\hline $1955-59$ to $1990-94$ & -110.0 & -59.9 & -15.3 & -2.7 & -41.9 \\
\hline \multicolumn{5}{|l|}{ Men } & -77.9 \\
\hline $1955-59$ & 422.3 & 235.9 & 144.0 & 0.8 & 91.2 \\
\hline $1960-64$ & 409.3 & 223.8 & 147.6 & 0.9 & 75.3 \\
\hline $1965-69$ & 401.5 & 217.1 & 151.6 & 1.0 & 64.5 \\
\hline $1970-74$ & 386.8 & 209.5 & 154.9 & 1.1 & 53.5 \\
\hline $1975-79$ & 367.3 & 194.7 & 151.2 & 1.2 & 42.4 \\
\hline $1980-84$ & 335.9 & 175.1 & 143.4 & 1.3 & 30.4 \\
\hline $1985-89$ & 305.5 & 156.9 & 131.1 & 1.4 & 24.3 \\
\hline 1990-94 & 284.5 & 143.3 & 120.1 & 1.5 & 21.6 \\
\hline \multicolumn{6}{|l|}{ Rate difference per 100000 person years from } \\
\hline $1955-59$ to $1990-94$ & 137.8 & -92.7 & -23.8 & 0.7 & -69.5 \\
\hline$\%$ change from $1955-59$ to $1990-94$ & -32.6 & -39.3 & -16.6 & 85.9 & -76.3 \\
\hline
\end{tabular}

${ }^{\star}$ Causes of death predominately avoidable through: primary prevention (group 1) early detection and treatment (group 2), and improved treatment and medical care (group 3). †Age standardised rates (world population) per 100000 person years.

five year period for which data were available. The 1960 crude male death rate for group one causes was 161.4 per 100000 with the missing data counted as zero, and 162.1 per 100000 with the imputed data, a difference of 0.7 per 100 000. However, to minimise the underesti-
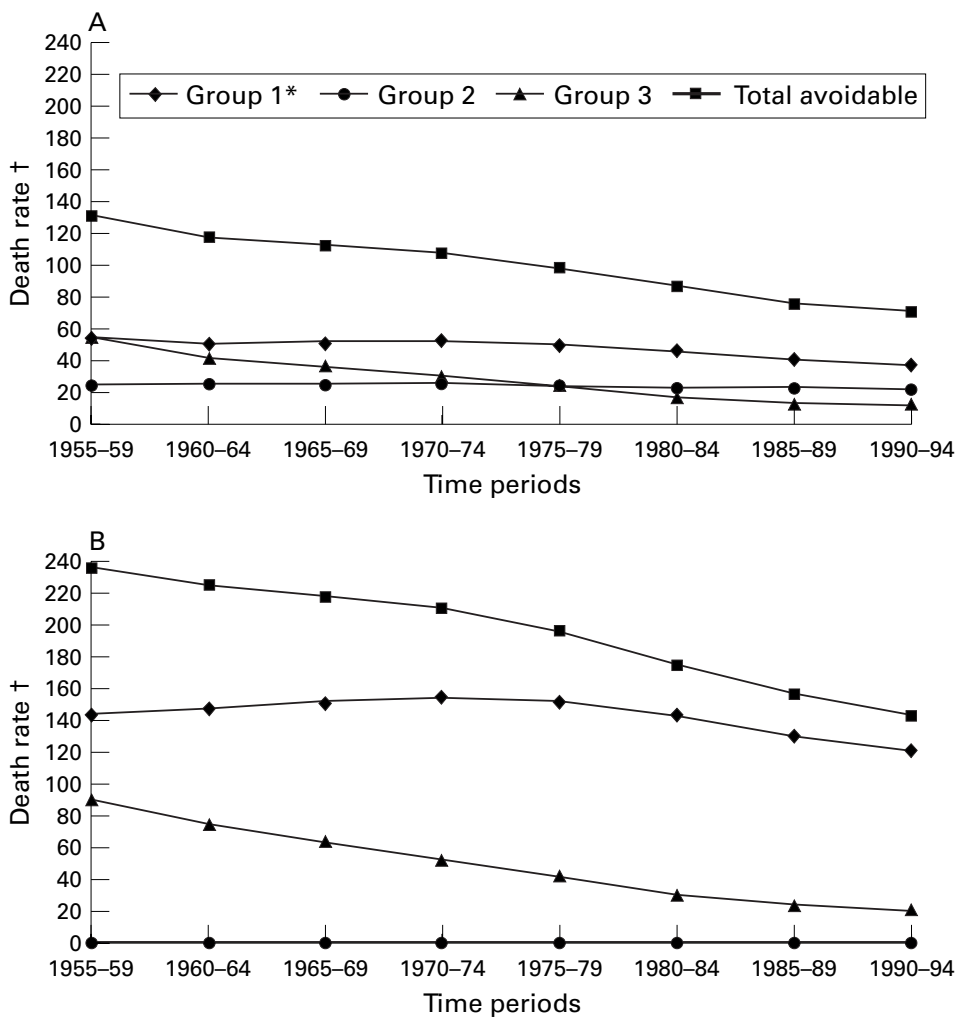

Figure 1 Time trends of avoidable death rates by five year time periods, 1955-59 to. 1990-94, Europe, ages 5-64. *Groups of causes predominately avoidable through: primary prevention (group 1), early detection and treatment (group 2), and improved treatment and medical care (group 3). + Age standardised rates (world population) per 100000 person years. mation of death rates that may arise from counting missing data as zero deaths, for calculation of rates we substituted the zeros for each year of missing data with the average annual number of deaths derived from the next five year period for which data were available.

\section{Results}

Table 3 lists the trends in death rates for overall mortality, for total avoidable causes and for avoidable cause groups 1-3 for European women and men aged 5-64 in five year time periods from 1955-59 to 1990-94. Group one represents mortality that is avoidable through primary prevention, group two through early recognition and treatment (secondary prevention), and group three through improved treatment and medical care (tertiary prevention). Between 1955-59 and 1990-94, the reduction in mortality was somewhat greater for avoidable causes than for all causes: $45.8 \% v 45.1 \%$ among women, and $39.3 \% v 32.6 \%$ among men. The total male avoidable mortality remained approximately twice that of the total female avoidable mortality throughout the study period. Among women, the greatest reduction in avoidable mortality over the study period was seen in group three causes $(77.9 \%$ reduction) and the least from group two causes (11.0\% reduction). Among men, greater reductions in male avoidable mortality were seen from group three causes $(76.3 \%)$ compared with group one causes $(16.6 \%)$. Male death rates in group two are minimal as the only cause of death included is skin cancersmelanoma and non-melanoma; the other causes in group two are female cancers. Figure 1 depicts the time trends of age standardised avoidable mortality rates across the 40 year study period for women (A) and men (B).

Figures 2 and 3 show the time trends of avoidable mortality for each of the four European regions by sex. In general, relatively few interregional differences were observed. Among women across the four regions (fig 2), southern Europe had the highest overall rate of total avoidable mortality in the first time period (1955-59), and the lowest rates by the final time period (1990-94). Northern European women had the highest rates across most of the later time periods for secondary and tertiary prevention causes as well as for total avoidable mortality. Among men (fig 3), northern Europeans showed the greatest reduction in total avoidable mortality and had the lowest absolute rates in the final three time periods (1980-84 to 1990-94). For primary prevention causes, all regions experienced a rise in rates in the 1970s. Over the entire study period, however, reductions in mortality for this group of causes was greater in northern and central Europe than in the Nordic countries or in southern Europe.

There may be individual conditions within the avoidable cause groups that exert an influence on the mortality trends, such as lung cancer among men (group one), and breast cancer among women (group two). Table 4 lists the death rates over the study period for these two conditions as well as the contribution of these 

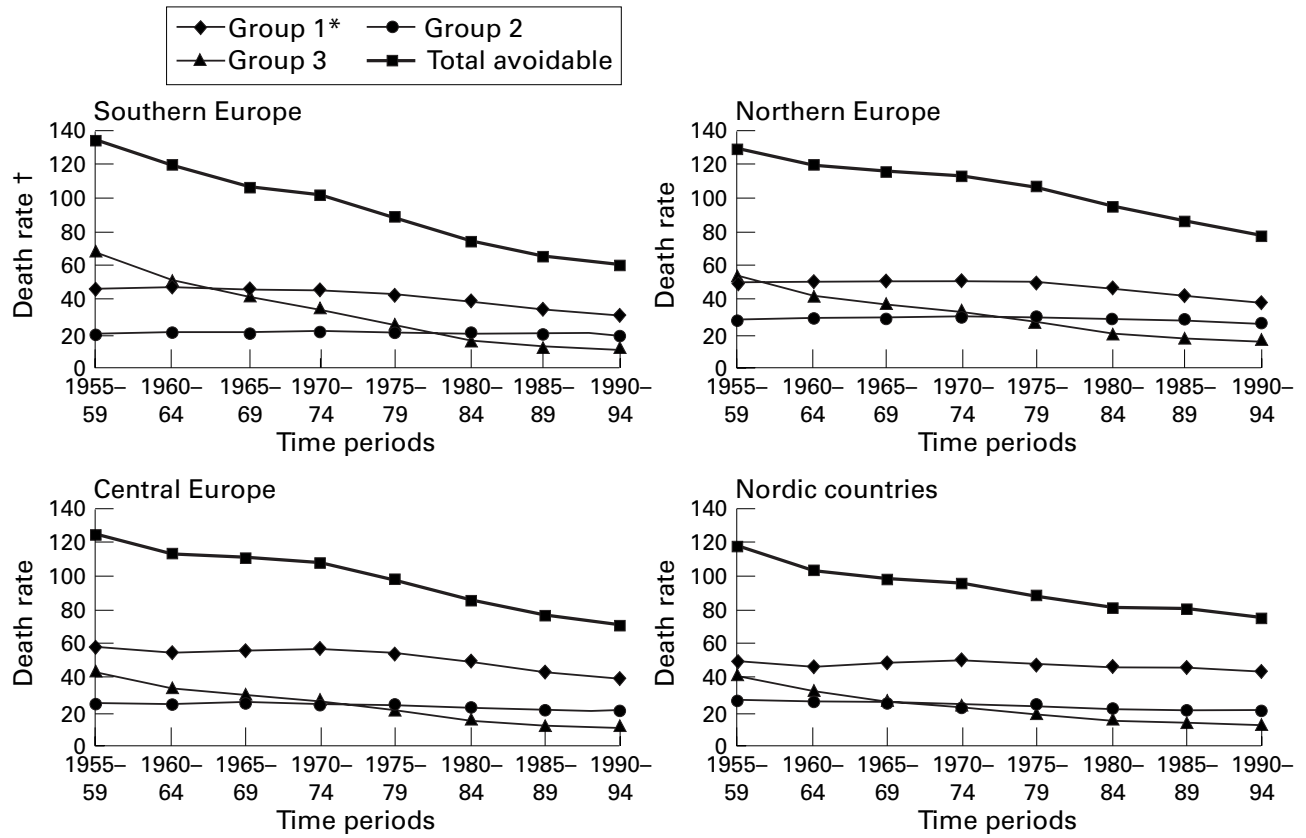

Figure 2 Time trends of avoidable death rates by five year time periods, 1955-59 to 1990-94 for women, ages 5-64. ${ }^{\star}$ Groups of causes predominately avoidable through: primary prevention (group 1), early detection and treatment (group 2), and improvements in treatment and medical care (group 3). +Age standardised rates (world population) per 100000 person years.

conditions to mortality in the avoidable cause groups to which they belong. Male lung cancer death rates increased slowly through 1984, with a small decline evident only in the last time period, 1990-94. The contribution of lung cancer to the total mortality burden of group one causes for men 5-69 years of age increased from $15.5 \%$ during 1955-59 to $21.3 \%$ during 1990-94 (table 4). While lung cancer rates for women remained low compared with those for men, their contribution to the total mortality burden of group one increased from $5.7 \%$ to $16.1 \%$ over the study period (table 4). When excluding lung cancer from group one causes, male death rates from 1955-59 to $1990-94$ declined by $22.4 \%$ compared with $16.6 \%$ with lung cancer included, as reported in table 1. Female group one death rates without lung cancer declined by $36.9 \%$ compared with $29.1 \%$ with lung cancer included. The pattern of group one mortality with respect to total avoidable mortality or to the other groups of causes was not changed when lung cancer deaths were excluded (data
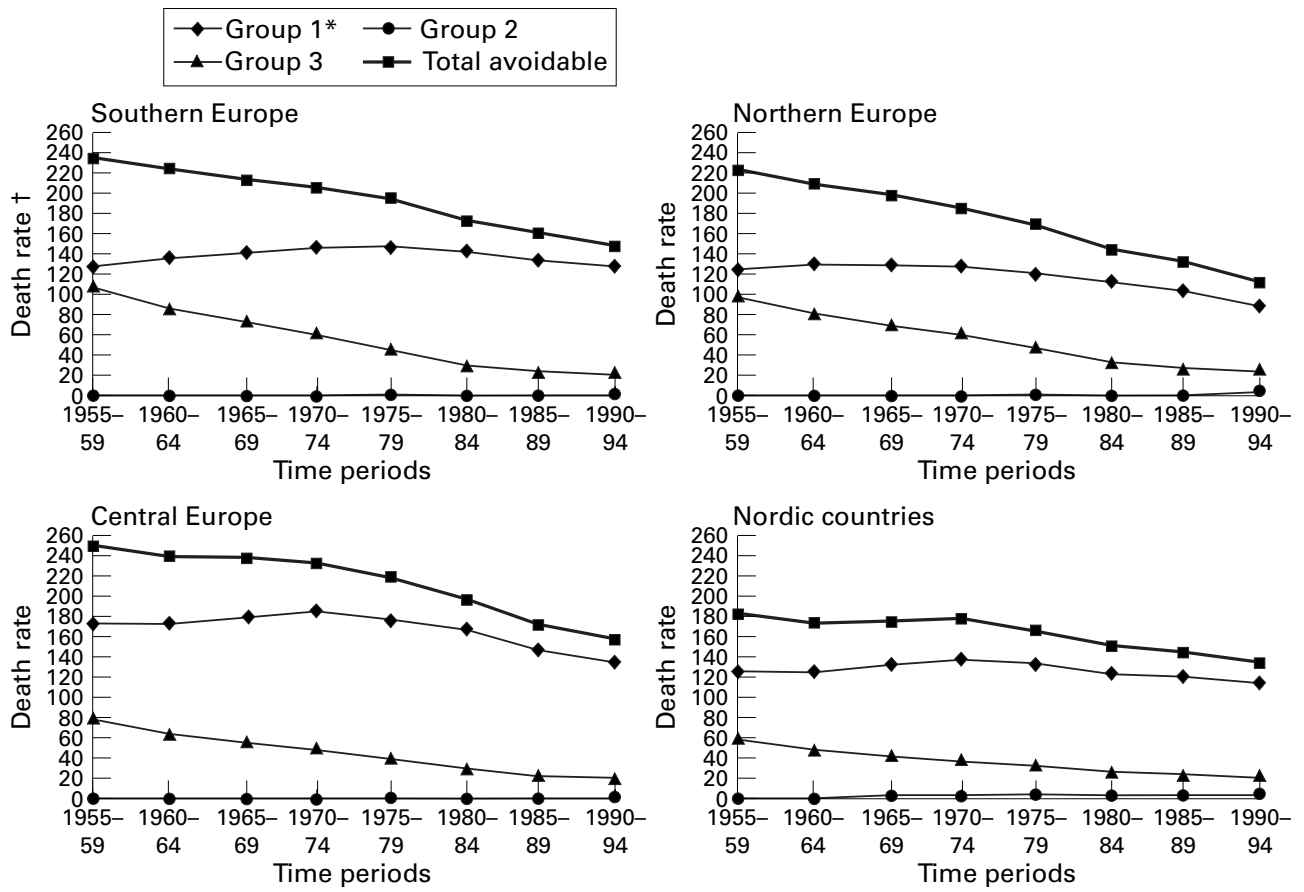

Figure 3 Time trends of avoidable death rates by five year time periods, 1955-59 to 1990-94 for men, ages 5-64. 
Table 4 Death rates for breast cancer (women) and lung cancer (men and women) in Europe for years 1955-1994, ages 5-64

\begin{tabular}{|c|c|c|c|c|c|c|}
\hline \multirow[b]{3}{*}{$\begin{array}{l}\text { Time } \\
\text { periods }\end{array}$} & \multicolumn{4}{|c|}{ Lung cancer } & \multirow{2}{*}{\multicolumn{2}{|c|}{$\begin{array}{l}\text { Breast cancer } \\
\text { Women }\end{array}$}} \\
\hline & \multicolumn{2}{|l|}{ Women } & \multicolumn{2}{|l|}{ Men } & & \\
\hline & $\begin{array}{l}\text { Death } \\
\text { rates }\end{array}$ & $\begin{array}{l}\% \text { of group } 1 \\
\text { causest }\end{array}$ & $\begin{array}{l}\text { Death } \\
\text { rates }\end{array}$ & $\begin{array}{l}\% \text { of group } 1 \\
\text { causes }\end{array}$ & $\begin{array}{l}\text { Death } \\
\text { rates }\end{array}$ & $\begin{array}{l}\% \text { of group } 2 \\
\text { causes }\end{array}$ \\
\hline $1955-59$ & 3.0 & 5.7 & 22.2 & 15.4 & 12.9 & 53.3 \\
\hline $1960-64$ & 3.4 & 6.7 & 24.9 & 16.9 & 13.7 & 55.9 \\
\hline $1965-69$ & 3.8 & 7.4 & 26.0 & 17.2 & 14.7 & 59.5 \\
\hline $1970-74$ & 4.1 & 7.9 & 26.6 & 17.2 & 15.9 & 64.6 \\
\hline $1975-79$ & 4.6 & 9.3 & 27.9 & 18.5 & 16.2 & 68.3 \\
\hline $1980-84$ & 5.0 & 11.0 & 28.3 & 19.7 & 16.7 & 73.1 \\
\hline $1985-89$ & 5.4 & 13.4 & 28.1 & 21.4 & 17.1 & 76.2 \\
\hline $1990-94$ & 6.0 & 16.1 & 25.6 & 21.3 & 16.9 & 78.4 \\
\hline
\end{tabular}

^Age standardised rates (world population) per 100000 person years. †Causes of death predominately avoidable through: primary prevention (group 1) and early detection and treatment (group 2).

not shown). Female breast cancer mortality steadily increased both by absolute rates and by its contribution to group two causes of death over the study period, from $53.3 \%$ in $1955-59$ to $78.0 \%$ in $1990-94$ (table 4 ). The exclusion of breast cancer from the analysis of avoidable mortality trends influenced the outcome: without breast cancer, the reduction in group two mortality over the study period was $58.9 \%$ instead of $11.0 \%$ as was reported in table 1 . In addition, by excluding breast cancer, death rates from group two causes did not exceed those from group three causes starting during $1975-79$, as occurred when breast cancer was included in the analysis (fig 1). While mortality from breast cancer increased in Europe over the study period, mortality from cervical (or related) cancers declined. Attempting to demonstrate a screening effect, we compared European death rates for cervical cancer (ICD9 179-80,182) and for breast cancer (ICD9 174) in two time periods roughly corresponding to the initiation of mass cancer screening programmes. For the period 1955 to 1974 , the standardised death rate from cervical cancer was 9.4 per 100000 person years compared with 5.0 per 100000 person years for the period 1975-1994. By contrast, the breast cancer death rate during the period 1955-1979 was 14.7 compared with 16.8 for the period 1980-1994.

\section{Discussion}

In the current analysis, the most dramatic decline in mortality of the three groups of avoidable mortality was seen in group three, causes of death avoidable through improvements in treatment and medical care. This finding is consistent with other time trend studies of avoidable mortality using similar causes of death. ${ }^{3112021}$ Mortality from group three declined less rapidly for men than for women, which may be in part because of a more striking reduction of maternal mortality than of other conditions included in group three. It may also reflect that mortality from certain conditions in group three, such as hypertension, is influenced as much by individual risk factors like tobacco use as by the quality of medical care.

This study has made important contributions to the investigation of avoidable mortality through inclusion of female breast cancer and
KEY POINTS

- Causes of avoidable mortality may be considered preventable through reduction of exposures, early detection or improved treatment.

- For European men, the main causes of avoidable mortality are those related to tobacco, diet, and occupational exposures.

- For European women, the main causes of avoidable mortality are cancers that are preventable through screening.

- Measures are necessary to reduce the burden of avoidable causes such as tobacco control and universal cancer screening for women.

categorisation of causes of death by level of prevention. Most previous investigations have viewed avoidable causes of mortality as an indicator of the adequacy of health care resources or the quality and availability of medical interventions across geographical units, ${ }^{25} 6922-25$ across social classes, ${ }^{2819}$ and over time. ${ }^{3112021}$ Thus, the major neoplasms most commonly listed as avoidable causes of death in these published investigations, trachea, bronchus and lung, bladder, and cervical cancer, were included to relate their distribution over time and area with medical intervention and not with primary or secondary prevention. ${ }^{12}$ However, Rutstein's original list of sentinel causes of avoidable deaths did list tumours of the mouth and oral cavity, larynx, lung, skin and bladder as conditions that may also be avoidable through primary prevention, especially through the reduction of environmental and occupational exposures. ${ }^{1}$ The European Community Atlas of Avoidable Deaths presents separate tables for three primary prevention conditions-lung cancer, cirrhosis of the liver, and motor vehicle accidents. ${ }^{10}$ Westerling ${ }^{26}$ included several preventable conditions from Rutstein's list ${ }^{1}$ and added "other diseases of the liver". Gaižauskiené and Westerling ${ }^{25}$ included motor vehicle accidents in their list of avoidable causes for a comparison of Lithuania and Sweden. Female breast cancer deaths, one third of which are preventable through regular mammographic screening $^{27}$ and one of the major causes of death among women over 50, were not included among avoidable deaths in any of the above cited publications.

There are several limitations to this study that may influence the conclusions. Variations in the quality of coding of causes of death within individual countries may have limited the overall accuracy of the death rates; however, grouping causes into broad categories and countries into broad regions should have lessened the variation caused by error. In addition to problems with comparability of data, aggregate studies of avoidable mortality across geographical regions may be difficult to interpret because of uncontrolled confounding by socioeconomic factors that affect the availability and quality of health services, and 
thus mortality. ${ }^{10} \mathrm{~A}$ further limitation is that not all preventable conditions were included in our grouping of avoidable causes, especially those causes with unexplained declines in mortality such as gastric cancer and colorectal cancers, whose preventive agents may well be related to diet. ${ }^{28}$ However, our groups included the tumours that have the highest mortality and that are avoidable at least in part from reduction of specific exposures or from early detection and treatment; most importantly, malignant neoplasms of the trachea, bronchus, and lung for both men and women and malignant neoplasms of the female breast.

The findings from this analysis of avoidable mortality in Europe highlight the uneven decline in mortality over time by sex and by cause of death. Benefits from improvements in treatment and medical care can clearly be seen by the rapid decline of causes included in group three. However, the decline in mortality has been less dramatic for conditions that are avoidable through beneficial changes in lifestyle (for example, better diet, weight reduction, smoking cessation, and limiting alcohol intake) or through reductions of social and economic inequalities among groups of people that affect health, such as environmental and occupational exposures or differential access to screening services. These causes were represented by groups one and two in our analysis. Primary prevention of mortality entails measures to reduce human exposure to the main risk factors. Tobacco is the single most important factor contributing to cancer deaths. ${ }^{29}$ According to a descriptive model of the cigarette epidemic, many countries in Europe have begun to see a reduction in the incidence of male lung cancer. ${ }^{30}$ However, the lag period of 3-4 decades between the decline in smoking incidence and the decline in smoking attributable mortality means that smoking related deaths will continue to make an important contribution to the mortality from avoidable causes, particularly among women, ${ }^{31}$ as shown in this study. Based on indirect estimation of mortality, female death rates from tobacco will continue to accelerate over the next few decades in developed countries. ${ }^{32}$ As a group, countries of the European Community have the highest number of annual tobacco attributable deaths of all developed countries, with up to an estimated 570000 deaths from tobacco per year during the $1990 \mathrm{~s} .^{32}$ Other modifiable risk factors for avoidable deaths include diet, considered to be responsible for between one quarter and one third of all cancers, ${ }^{33}$ and alcohol consumption, which has been shown to be causally related to cancers of the oral cavity, oesophagus, and pharynx and is also a major risk factor for cirrhosis of the liver. ${ }^{34}$ Early detection and treatment for breast cancer and cervical cancer has been shown to reduce mortality from these cancers. ${ }^{27} 35$ Screening activities for breast and cervical cancer, however, are not universally available in Europe and women of appropriate ages for effective screening may be the least served by spontaneous screening. ${ }^{36}{ }^{37}$ This may explain in part the finding that for group two causes of death among European women, among which the most important cause is breast cancer, mortality reduction was only $11.0 \%$ between 1955 and 1994.

In conclusion, avoidable mortality in Europe for the years 1955-94 shows a clear decline that is mainly because of improved treatment and medical care. Primary prevention does not seem to have played an important part in reducing mortality, either for men or for women, and expected reductions in female mortality from causes amenable to screening, in particular breast cancer, are not yet evident. This negative result can be considered an important consequence of the limited public health activities in effect in the European countries included in this analysis. The goal of a further reduction of mortality can in fact be achieved through implementation of primary and secondary prevention activities. Antitobacco policies are among the most cost effective measures to improve health and should be considered to be in the national interest of individual countries to support such programmes. $^{38}$ Efforts should continue to identify occupational and environmental carcinogens and to regulate exposures to and emissions of these substances into the environment, and to provide universal access to screening programmes for breast and cervical cancer among women.

The authors would like to thank Dr Mariangela Mazzi for her statistical assistance and the anonymous reviewers for their clarifying comments on drafts of this article.

Funding: the study was supported by grants from the Italian Ministry of Education (MURST $60 \%$ ) and the Italian Association for Reasearch on Cancer (AIRC).

1 Rutstein DD, Berenberg W, Chalmers TC, et al. Measuring the quality of medical care. A clinical method. N Engl f Med 1976;294:582-8.

2 Charlton JRH, Hartley RM, Silver R, et al. Geographical variation in mortality from conditions amenable to medical variation in mortality from conditions amenable to medical

3 Poikolainen K, Eskola J. The effect of health services on mortality: decline in death rates from amenable and non-amenable causes in Finland, 1969-81. Lancet 1986;i: non-amen

Holland WW. The 'avoidable death' guide to Europe. Health Policy 1986;6:115-17.

5 Mackenbach JP, Kunst AE, Looman CWN, et al. Regional differences in mortality from conditions amenable to medical intervention in The Netherlands: a comparison of four time periods. F Epidemiol Community Health 1988;42:32532.

6 de Marco R, Zanolin ME. Mortalità per alcune cause riconducibili all'intervento medico nelle Usl lombarde (19801985). Epidemiol Prev 1990;45:24-32.

7 Westerling R, Smedby B. The European Community "Avoidable Death Indicators" in Sweden 1974-1985. Int 7 Epidemiol 1992;21:502-10.

8 Marshall SW, Kawachi I, Pearce N, et al. Social class differences in mortality from diseases amenable to medical intervention in New Zealand. Int $\mathcal{F}$ Epidemiol 1993;22:25561 .

9 Bellini P, Simonato L, Maggiolo G. La Mortalità Evitabile Nel Veneto. Padova: CLEUP, 1994.

10 European Community Working Group on Health Services and "Avoidable Deaths". European Community Atlas of "Avoidable Death". 2nd ed. Vol 1. Oxford: Oxford University Press, 1991

11 Charlton JRH, Velez R. Some international comparisons of mortality amenable to medical intervention. BMF 1986; 292:295-301.

12 Mackenbach JP, Bouvier-Colle MH, Jougla E. "Avoidable" mortality and health services: a review of aggregate data studies. I Epidemiol Community Health 1990;44:106-11.

13 Ahrens W, Jöckel K-H, Patzak W, et al. Alcohol, smoking and occupational factors in cancer of the larynx: a case-control study. Am F Ind Med 1991;20:477-93.

14 Boffetta P, Kogevinas M, Simonato L, et al. Current Boffetta $\mathrm{P}$, Kogevinas $\mathrm{M}$, Simonato $\mathrm{L}$, et al. Current
perspectives on occupational cancer risks. Int f Occup Enviperspectives on occupation

15 Antilla A, Heikkilä P, Pukkala E, et al. Excess lung cancer among workers exposed to lead. Scand $\mathcal{F}$ Work Environ Health 1995;21:460-9. 
16 Simonato L, Boffetta P, Kogevinas M. Epidemiological aspects of cancer risk associated with exposure in the occu-
pational environment. Med Lav 1996;87:5-15.

17 Consensus Development Panel - Commission of Early Detection and Prevention of Skin Cancer. How to decrease morbidity and mortality of skin cancer: primary prevention of skin cancer/screening of skin cancer. Eur $\mathcal{F}$ Cancer Prev 1996;5:297-9.

18 Marks R. Prevention and control of melanoma:The public health approach. CA Cancer F Clin 1996;46:199-216.

19 Mackenbach JP, Stronks K, Kunst AE. The contribution of medical care to inequalities in health: differences between socio-economic groups in decline of mortality from conditions amenable to medical intervention. Soc Sci Med 1989; 29:369-76.

20 Mackenbach JP, Looman CWN, Lunst AE, et al. Post-1950 mortality trends and medical care: gains in life expectancy due to declines in mortality from conditions amenable to medical intervention. Soc Sci Med 1988;27:889-94.

21 Gil LM, Rathwell T. The effect of health services on mortality: amenable and non-amenable causes in Spain. Int mortality: amenable and non

22 Carr-Hill RA, Hardman GF, Russell IT. Variations in avoidable mortality and variations in health care resources. Lancet $1987 ; \mathrm{i}: 789-92$.

23 Poikolainen K, Eskola J. Health services resources and thei relation to mortality from causes amenable to health care intervention: a cross-national study. Int $f$ Epidemio 1988:17:86-9.

24 Morosini PL, Lauriola P, Magliola E, et al. Le morti evitabili nella valutazione dell'attività del servizio sanitario. Epidemiol Prev 1990;45:48-58.

25 Gaižauskiené A, Westerling R. A comparison of avoidable mortality in Lithuania and Sweden 1971-1990. Int $\mathcal{F}$ Epidemiol 1995;24:1124-31
26 Westerling R. Trends in "avoidable" mortality in Sweden, 1974-1985. F Epidemiol Community Health 1992;46:489-93. 1974-1985. F Epidemiol Community Health 1992;46:489-93.
Fletcher SW, Black W, Harris R, et al. Report of the International Workshop on Screening for Breast Cancer. $\mathcal{F}$ Natl Cancer Inst 1993;85:1644-56.

28 Howson CP, Hiyama T, Wynder EL. The decline in gastric cancer: epidemiology of an unplanned triumph. Epidemiol Rev 1986;8:1-27.

29 Doll R, Peto R. The causes of cancer. Oxford: Oxford University Press, 1981

30 Coleman MP, Esteve J, Damiecki P, et al. Trends in cancer incidence and mortality. IARC Scientific Publications no 21. Lyon: International Agency for Research on Cancer, 1993:311-42.

31 Beckett WS. Epidemiology and etiology of lung cancer. Clin Chest Med 1993;14:1-15.

32 Peto R, Lopez AD, Boreham J, et al. Mortality from tobacco in developed countries: indirect estimation from national vital statistics. Lancet 1992;339:1268-78.

33 Willet WC, Trichopoulos D. Nutrition and cancer: A summary of the evidence. Cancer Causes Control 1996;7:17880 .

34 International Agency for Research on Cancer. IARC monographs on the evaluation of carcinogenic risks to humans: alcohol drinking. Vol 44. Lyon: IARC, 1988:153-250.

35 Miller AB, Anderson G, Brisson J, et al. Report of a national workshop on screening for cancer of the cervix. Can Med Assoc F 1991;145:1301-25.

36 Milburn K, MacAskill S. Cervical screening: continuing oncerns in the 1990s. Health Education fournal 1994;53: 201-13.

37 Shapiro S. Periodic breast cancer screening in seven foreign countries. Cancer 1992;69 (suppl):1919-24.

38 Barnum $\mathrm{H}$. The economic burden of the global trade in tobacco. Tobacco Control 1994;3:358-61. 